\title{
Papers
}

\section{What are the symptoms of varicose veins? Edinburgh vein study cross sectional population survey}

\author{
Andrew Bradbury, Christine Evans, Paul Allan, Amanda Lee, C Vaughan Ruckley, F G R Fowkes
}

\begin{abstract}
Objective To define the relations between age, sex, lower limb symptoms, and the presence of trunk varicose veins on clinical examination.

Design Cross sectional population study. Setting 12 general practices with catchment areas geographically and socioeconomically distributed throughout Edinburgh.

Participants An age stratified random sample of 1566 people (699 men and 867 women) aged 18-64 selected from the computerised age-sex registers of participating practices.

Main outcome measures Self administered questionnaire on the presence of lower limb symptoms and physical examination to determine the presence and severity of varicose veins.

Results Women were significantly more likely than men to report lower limb symptoms such as heaviness or tension, swelling, aching, restless legs, cramps, and itching. The prevalence of symptoms tended to increase with age in both sexes. In men, only itching was significantly related to the presence and severity of trunk varices (linear test for trend, $\mathrm{P}=0.011$ ). In women there was a significant relation between trunk varices and the symptoms of heaviness or tension $(\mathrm{P} \leqslant 0.001)$, aching $(\mathrm{P} \leqslant 0.001)$, and itching $(\mathrm{P} \leqslant 0.005)$. However, the level of agreement between the presence of symptoms and trunk varices was too low to be of clinical value, especially in men.

Conclusions Even in the presence of trunk varices, most lower limb symptoms probably have a non-venous cause. Surgical extirpation of trunk varices is unlikely to ameliorate such symptoms in most patients.
\end{abstract}

\section{Introduction}

Varicose veins are commonly stated to be responsible for a wide range of lower limb symptoms such as heaviness, swelling, aching, restless legs, cramps, itching, and tingling. ${ }^{1-5}$ The presence of one or more of these symptoms, together with clinical or ultrasound evidence of main stem saphenous reflux, is generally accepted as an indication for surgery. Epidemiological studies have suggested that up to $15 \%$ of men and $25 \%$ of women have visible varicose veins. ${ }^{6}$ Although it has not been studied, an equally large proportion of the adult population may be affected by various lower limb symptoms. A cause and effect relation between uncomplicated trunk varices and lower leg symptoms has not been proved, and little evidence exists that removing varicose veins ameliorates any of these symptoms. ${ }^{7}$

The relation between lower limb symptoms and varicose veins is not just of academic interest but is of direct clinical and economic importance to the NHS. More than 50000 varicose vein operations are performed each year in England and Wales, ${ }^{8}$ and the direct annual cost to the NHS of treating chronic venous insufficiency is estimated at $£ 400-600 \mathrm{~m}^{9}$ Although varicose vein surgery is generally straightforward, complications can occur, including recurrence, and it should not be performed for inappropriate indications. Despite this, few epidemiological studies have investigated the full range of venous symptoms and signs in the general population. ${ }^{10}$ Most studies have been restricted to ulceration ${ }^{11}$ or to specific subject groups $^{12}$ rather than a true cross section of the general population.

The primary aim of the Edinburgh vein study was to conduct a detailed population survey of the prevalence of all grades of venous disease in a randomly selected, age stratified sample of the adult population. This paper examines the relation between age, sex, lower limb symptoms, and the presence and severity of varicose veins on clinical examination.

\section{Participants and methods}

The Edinburgh vein study is a cross sectional survey of men and women aged 18 to 64 years resident in Edinburgh, Scotland. An age stratified random sample was selected from the computerised age-sex registers of 12 general practices with catchment areas geographically and socioeconomically distributed throughout the city. We estimated that a total sample size of 1500 participants was needed to detect a significant difference in prevalence between groups and to enable a subsequent follow up study to be conducted.

Equal numbers of men and women were invited to participate in the study; $21.3 \%$ of the initial invitations were sent to subjects in each of the four 10-year age bands (25-34, 35-44, 45-54, 55-64 years) and 14.8\% to subjects in the youngest age band (18-24 years), which spanned seven years. Of 2912 people contacted, 1566 participated giving a response rate of $53.8 \%$. The response rate increased with age and was slightly higher in women than men. Overall, the ethnic origin

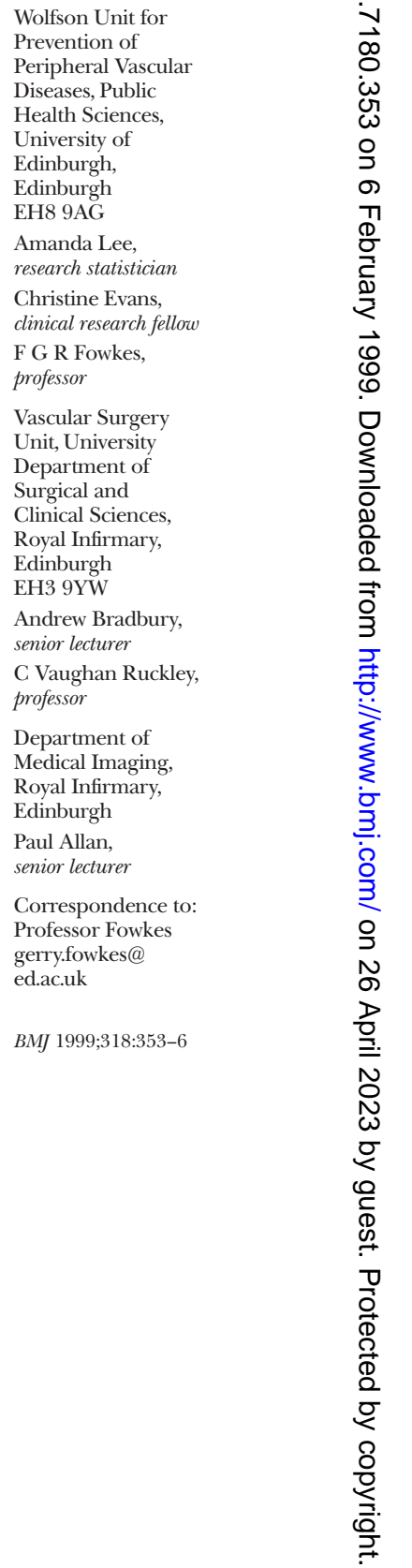


Table 1 Classification used for examination of legs in Edinburgh vein study (adapted from Widmer ${ }^{14}$ )

\begin{tabular}{ll} 
Category & Definition \\
\hline Trunk varices & $\begin{array}{l}\text { Dilated, tortuous trunks of the long or short saphenous vein or their first } \\
\text { or second order branches }\end{array}$ \\
\hline Reticular varices & $\begin{array}{l}\text { Dilated, tortuous, subcutaneous veins not belonging to the main trunk or } \\
\text { its major branches }\end{array}$ \\
\hline Hyphenweb varices & Intradermal varices (venous telangiectasia) \\
\hline
\end{tabular}

All three categories were graded depending on the degree and extent of tortuosity and prominence of veins by using standard reference photographs

Table 2 Number (percentage) of men and women with leg symptoms by age group

\begin{tabular}{lcccc} 
& \multicolumn{3}{c}{ Age (years) } & \\
\cline { 2 - 4 } Leg symptoms & $\mathbf{1 8 - 3 4}$ & $\mathbf{3 5 - 5 0}$ & $\mathbf{5 1 - 6 4}$ & P value* \\
\hline Men & $\mathrm{n}=142$ & $\mathrm{n}=274$ & $\mathrm{n}=283$ & \\
\hline Heaviness or tension & $21(15)$ & $42(15)$ & $49(17)$ & $>0.05$ \\
\hline Feeling of swelling & $3(2)$ & $23(8)$ & $39(14)$ & $\leqslant 0.001$ \\
\hline Aching & $43(30)$ & $78(29)$ & $105(38)$ & $>0.05$ \\
\hline Restless legs & $33(23)$ & $45(16)$ & $63(22)$ & $>0.05$ \\
\hline Cramps & $38(27)$ & $82(30)$ & $118(42)$ & $\leqslant 0.001$ \\
\hline Itching & $28(20)$ & $44(16)$ & $61(22)$ & $>0.05$ \\
\hline Tingling & $21(15)$ & $43(16)$ & $48(17)$ & $>0.05$ \\
\hline Women & $\mathrm{n}=210$ & $\mathrm{n}=323$ & $\mathrm{n}=334$ & \\
\hline Heaviness or tension & $51(24)$ & $101(32)$ & $94(28)$ & $>0.05$ \\
\hline Feeling of swelling & $31(15)$ & $84(26)$ & $81(25)$ & 0.02 \\
\hline Aching & $99(47)$ & $182(57)$ & $184(55)$ & $>0.05$ \\
\hline Restless legs & $50(24)$ & $108(34)$ & $143(43)$ & 0.001 \\
\hline Cramps & $79(38)$ & $131(41)$ & $152(46)$ & $>0.05$ \\
\hline Itching & $41(20)$ & $85(27)$ & $92(28)$ & 0.045 \\
\hline Tingling & $44(21)$ & $67(21)$ & $60(18)$ & $>0.05$ \\
\hline
\end{tabular}

*Test for linear trend across age groups.

Table 3 Age adjusted prevalence (\%) of leg symptoms in men and women

\begin{tabular}{lccc} 
Leg symptoms & Men $(\mathbf{n}=\mathbf{6 9 9})$ & Women $\mathbf{( n = 8 6 7 )}$ & P value \\
\hline Heaviness or tension & 16.0 & 28.6 & $\leqslant 0.01$ \\
\hline Feeling of swelling & 9.2 & 23.0 & $\leqslant 0.01$ \\
\hline Aching & 32.5 & 53.8 & $\leqslant 0.01$ \\
\hline Restless legs & 20.0 & 35.1 & $\leqslant 0.01$ \\
\hline Cramps & 34.0 & 42.0 & $\leqslant 0.01$ \\
\hline Itching & 19.0 & 25.3 & $\leqslant 0.01$ \\
\hline Tingling & 16.0 & 19.8 & 0.084 \\
\hline
\end{tabular}

and social class of participants were similar to those of the general Edinburgh population except that a slightly higher proportion of participants were from the upper socioeconomic classes (social class I 10.8\% $v$ $8.5 \%$; class II $37.0 \%$ v 30.4\%). Follow up of a sample of 194 non-respondents suggested that participants were more likely to have a history of diagnosed venous disease than the general population. Details of the methods and response rate in the study have been reported. ${ }^{13}$ Local ethics committee approval for the study was granted and informed consent was obtained from each participant.

Subjects were invited to attend a research clinic at the University of Edinburgh on specific evenings and weekdays between May 1994 and April 1996. The clinic was staffed by one or more members of a research team comprising a nurse, technician, and medically qualified research fellow. Home visits were offered to those unable to attend. Participants completed a self administered questionnaire, which was then checked by a member of the research team. This questionnaire included a detailed inquiry into the presence of various symptoms which are often attributed to venous disease: heaviness or tension, a feeling of swelling, aching, restless legs, cramps, itching, and tingling. To determine intrasubject variability the symptom questionnaire was circulated twice to 62 people within this university department six weeks apart. Kappa values for intrasubject variability ranged from 0.42 (moderate) for tingling to 0.92 (almost perfect) for heaviness or tension.

After the participants had completed the questionnaire both legs were examined. The method of classification of venous disease was adapted from that used in the Basel study (table 1). ${ }^{14}$ Patients were examined standing after a delay of two minutes. Varices were graded 1 to 3 according to the "degree and extent of tortuosity and prominence of the veins" as previously described. ${ }^{13}$ Reference photographs were reviewed periodically as a reminder of the classifications, and the reliability of the observers in grading varicose veins from photographs was reviewed regularly throughout the study.

All data were entered on to a computer database and transferred to the Edinburgh University main frame computer for statistical analysis with SPSS- $\mathrm{x}$ and SAS statistical packages. The relation between the symptoms and either age group or clinical grade of venous disease was assessed by the Mantel-Haenszel test for linear trend. The GENMOD procedure and a macro (GLIMMIX), both from the SAS Institute, were used to fit generalised linear models in order to adjust the prevalences for age.

\section{Results}

A total of 1566 people attended for examination, 867 women and 699 men. The mean age of the participants was 44.8 years for women and 45.8 years for men.

The prevalence of many symptoms increased with age (table 2). In men, a feeling of swelling and cramps were significantly associated with increasing age (both $\mathrm{P} \leqslant 0.001)$. A feeling of swelling $(\mathrm{P}=0.02)$, restless legs $(\mathrm{P}=0.001)$, and itching $(\mathrm{P}=0.045)$ were all significantly more common in older women than younger women. Subsequent results were therefore adjusted for age.

Women were more likely than men to respond positively when asked about the presence of a wide range of lower limb symptoms (table 3). All sex differences were significant at the $1 \%$ level except for tingling $(\mathrm{P}=0.084)$. The commonest symptom was aching in women (53.8\%) and cramps in men (34.0\%). The least common symptom was tingling in women $(19.8 \%)$ and a feeling of swelling in men (9.2\%).

As there was no significant difference between right and left legs in any of the variables studied, only data for the right leg are presented in subsequent analyses. Table 4 shows the relation between the presence and grade of trunk varices on clinical examination and the age adjusted prevalence of symptoms in the right legs of men and women. In men, only itching was significantly related to the presence and severity of trunk varices $(\mathrm{P}=0.011)$. In contrast, there was a significant relation in women between the presence of trunk varices and heaviness or tension, aching (both $\mathrm{P} \leqslant 0.001)$, and itching $(\mathrm{P} \leqslant 0.005)$.

We found no significant association between the presence and grade of hyphenweb varices and lower limb symptoms in men (table 5), although there was a slight trend towards an increased feeling of swelling 
$(\mathrm{P}=0.070)$. In women hyphenweb varices were significantly associated with heaviness or tension and a feeling of swelling. No association was found between reticular varices and any lower limb symptom in either sex.

\section{Discussion}

Lower limb symptoms such as heaviness or tension, aching, a feeling of swelling, restless legs, cramps, itching, and tingling, which are often attributed to varicose veins, were extremely common in the general population whether or not varices were present. All these symptoms tended to increase with age and (except tingling) were significantly more common in women than in men. The age adjusted prevalence of trunk varices, which we have already reported in detail ${ }^{15}$ was higher in men (39.7\%) than women (32.2\%). Interestingly, in men there was no significant relation between trunk varices and any of the symptoms except itching. Even though there was an apparently strong relation between heaviness or tension, aching, and itching and the presence of trunk varices in women, this may be of limited clinical value. For example, although the linear trend between aching and trunk varices in women was significant $(\mathrm{P} \leqslant 0.001)$, aching was present in $45 \%$ of women without varices and $63 \%$ of those with grade 2 and 3 varices, a difference of only 18\%. Thus, not only do many asymptomatic patients have trunk varices on clinical examination but others experience a whole range of lower limb venous symptoms despite having little or no clinical evidence of venous disease. Such patients must be assumed to have either deep venous or non-venous disease to account for their symptoms.

These data are of direct relevance to clinicians and the bodies which fund health care. Although tens of thousands of varicose vein operations are performed in the United Kingdom each year, the scientific basis for this activity is lacking. There is limited evidence to support the contention that lower limb symptoms are caused by venous problems, even when varicose veins are visible, or that operating on simple varicose veins significantly improves these symptoms. ${ }^{7}$ Furthermore, operating on varicose veins before skin changes have developed has not been proved to reduce the socioeconomic burden of venous ulceration compared with a strategy of postponing surgery until the early skin changes of chronic venous insufficiency become apparent. It is therefore unsurprising that funding bodies in the United Kingdom are becoming increasingly reluctant to pay for the surgical treatment of venous disease.

\section{Who should be treated?}

Until the benefits (or lack of benefits) of varicose vein surgery are satisfactorily demonstrated by long term epidemiological and clinical studies, surgeons must attempt to identify those patients who have the most to gain from treatment. Our data suggest that if such decisions are based simply on the nature, severity, and chronicity of symptoms, or the extent and severity of varicosities on clinical examination, they are likely to be unreliable.

A significant proportion of patients with varicose veins seek an opinion because they are primarily concerned about the cosmetic appearance of their veins. Many such patients fear they may be denied treatment,
Table 4 Age adjusted prevalence (\%) of leg symptoms by presence and grade of trunk varices in the right legs of men and women

\begin{tabular}{lcccc} 
& \multicolumn{3}{c}{ Trunk varices } & \\
\cline { 2 - 4 } Leg symptoms & None & Grade $\mathbf{1}$ & Grades 2 or 3 & P value \\
\hline Men & $\mathrm{n}=\mathbf{4 7 6}$ & $\mathrm{n}=191$ & $\mathrm{n}=32$ & \\
\hline Heaviness or tension & 14.1 & 15.7 & 18.7 & $>0.1$ \\
\hline Feeling of swelling & 6.1 & 7.9 & 14.1 & 0.097 \\
\hline Aching & 28.4 & 27.0 & 27.0 & $>0.1$ \\
\hline Restless legs & 19.6 & 18.7 & 18.5 & $>0.1$ \\
\hline Cramps & 30.9 & 31.7 & 37.1 & $>0.1$ \\
\hline Itching & 15.8 & 18.3 & 37.6 & 0.011 \\
\hline Tingling & 12.4 & 13.2 & 15.8 & $>0.1$ \\
\hline Women & $\mathrm{n}=663$ & $\mathrm{n}=174$ & $\mathrm{n}=30$ & \\
\hline Heaviness or tension & 22.0 & 36.0 & 54.7 & $\leqslant 0.001$ \\
\hline Feeling of swelling & 17.6 & 21.6 & 24.6 & $>0.1$ \\
\hline Aching & 44.9 & 61.7 & 63.2 & $\leqslant 0.001$ \\
\hline Restless legs & 32.6 & 31.9 & 49.6 & $>0.1$ \\
\hline Cramps & 37.6 & 42.9 & 45.2 & $>0.1$ \\
\hline Itching & 20.6 & 27.5 & 38.0 & $\leqslant 0.005$ \\
\hline Tingling & 15.6 & 17.9 & 17.4 & $>0.1$ \\
\hline
\end{tabular}

${ }^{*}$ Test for linear trend across grade of trunk varices.

Table 5 Age adjusted prevalence (\%) of leg symptoms by presence and grade of hyphenweb varices in right legs of men and women

\begin{tabular}{lcccc} 
& \multicolumn{3}{c}{ Hyphenweb varices } & \\
\cline { 2 - 4 } Leg symptoms & None & Grade $\mathbf{1}$ & Grades 2 or 3 & P value * \\
\hline Men & $\mathrm{n}=144$ & $\mathrm{n}=519$ & $\mathrm{n}=36$ & \\
\hline Feeling of swelling & 2.6 & 8.2 & 6.0 & 0.070 \\
\hline Women & $\mathrm{n}=100$ & $\mathrm{n}=707$ & $\mathrm{n}=60$ & \\
\hline Heaviness or tension & 18.5 & 25.6 & 41.1 & 0.003 \\
\hline Feeling of swelling & 7.8 & 19.8 & 22.2 & 0.008 \\
\hline Restless legs & 24.9 & 33.6 & 36.9 & 0.080 \\
\hline
\end{tabular}

${ }^{*}$ Test for linear trend across grade of hyphenweb varices.

or receive a lower priority, if they do not complain of one or more lower limb symptoms. Taking a careful clinical history and advising a trial of support hosiery may determine which symptoms are of venous origin. However, even among those with genuine symptoms often the only way of establishing whether the patient will benefit from surgery is to operate and await the outcome. This is unsatisfactory, and a better understanding of the complex and inconsistent relations between symptoms and signs in patients with venous disease may allow scarce resources to be more appropriately focused.

In conclusion, the prevalence of so-called venous symptoms is extremely high in the general Edinburgh population, particularly in women. Symptoms are more closely associated with the presence of varices in women than in men, and certain symptoms seem more closely associated with venous disease than others. However, agreement between symptoms and signs in people with varicose veins is so poor that it may be of little value in determining whether symptoms are of venous origin or whether surgery will relieve them. Venous reflux was also measured in this population, ${ }^{16}$ and its correlation with symptoms will be reported later.

Background information was provided by Professor L K Widmer and Dr M-T Widmer. The data were collected by Mrs Eileen Kerracher and Mrs Maggie Carson. Mrs L Haggerty and Mrs A Murray provided secretarial and administrative support; Mr G Didcock and Mr T Blake provided computing support. The general practitioners, practice nurses, support staff and patients of the following Edinburgh general practices participated in the study: Dr White and partners; Milton Surgery; MacKenzie Medical Centre; Ladywell Medical Centre; Bruntsfield 
Key messages

- In this population survey women were more likely than men to report a wide range of lower limb symptoms

- In men, only itching was significantly related to the presence of trunk varices

- In women there was a significant relation between trunk varices and heaviness or tension, aching, and itching

- The level of agreement between the presence of symptoms and trunk varices is probably too low to be clinically useful

- A thorough clinical history and examination should be carried out before surgery

Medical Practice; Long House Surgery; Rose Garden Medical Centre; Crewe Medical Centre; Whinpark Medical Centre; Muirhouse Medical Group; and Dr Reid and partners.

Contributors: FGRF is the principal investigator and guarantor of the Edinburgh vein study. FGRF, CVR, CE, and PA planned the study and obtained funding. CE was the clinical coordinator. $\mathrm{AL}$ analysed the data, and all authors interpreted the results. $\mathrm{AB}$ wrote the paper with input from the other authors.

Funding: Wellcome Trust.

Competing interests: Limited results from the Edinburgh vein study were provided to a pharmaceutical company, for which the Wolfson Unit received consultancy fees and research funds.

1 Varicose veins. In: Forrest APM, Carter DC, MacLeod IB, eds. Principles and practice of surgery. Edinburgh: Churchill Livingstone, 1995:289-91.
2 Royle JP. Treatment of primary varicose veins. In: Bell PRF, Jamieson CW, Ruckley CV, eds. Surgical management of vascular disease. London: W B Saunders, 1992:1239-60.

3 Johnson G Jr, Rutherford RB. Varicose veins: patient selection and treatment. In: Rutherford RB, ed. Vascular surgery. London: W B Saunders, 1995:1895-8.

4 Tibbs DT. Venous disorders, vascular malformations, and chronic ulceration in the lower limbs. In: Morris PJ, Malt RA, eds. Oxford textbook of sur gery. Oxford: Oxford University Press, 1994:503-96.

5 Jones HJS, Derodra JK. Restless legs syndrome-a review. Eur J Vasc Endovasc Surg 1997;14:430-2.

6 Callam MJ. Epidemiology of varicose veins. BrJ Surg 1994;81:167-73.

7 Baker DM, Turnbull NB, Pearson JCG, Makin GS. How successful is varicose vein surgery? A patient outcome study following varicose vein surgery using the SF-36 health assessment questionnaire. Eur J Vasc Endovasc Surg 1995;9:299-304.

8 Department of Health and Social Security. Hospital episode statistics 198788. London: DHSS, 1988.

9 Ruckley CV. Socio-economic impact of chronic venous insufficiency and leg ulcers. Angiology 1997;48:67-9.

10 Fowkes FGR. Epidemiology of venous disease. Phlebology 1996;11:2-5.

11 Nelzen O, Bergqvist D, Lindhagen A. The prevalence of chronic lower-limb ulceration has been underestimated: results of a validated population questionnaire. BrJ Surg 1996;83:255-8.

12 Nelzen O, Bergqvist D, Fransson I, Lindhagen A. Prevalence and aetiology of leg ulcers in a defined population of industrial workers. Phlebology 1996;11:50-4.

13 Evans CJ, Fowkes FGR, Ruckley CV, Lee AJ. Edinburgh vein study. Methods and response in a survey of venous disease in the general population. Phlebology 1997;12:127-35.

14 Widmer LK, ed. Peripheral venous disorders-prevalence and socio-medical importance. Berne: Hans Gruber, 1978:1-90.

15 Evans CJ, Fowkes FGR, Ruckley CV, Lee AJ. Prevalence of varicose veins and chronic venous insufficiency in men and women in the general population: Edinburgh vein study. J Epidemiol Comm Health (in press).

16 Evans CJ, Allan PL, Lee AJ, Bradbury AW, Ruckley CV, Fowkes FGR. Prevalence of venous reflux in the general population on duplex scanning: the Edinburgh vein study. J Vasc Surg (in press).

(Accepted 10 November 1998)

\title{
Withdrawing low risk women from cervical screening programmes: mathematical modelling study
}

\author{
C Sherlaw-Johnson, S Gallivan, D Jenkins
}

Clinical

Operational

Research Unit,

Department of

Mathematics,

University College

London, London

WC1E 6BT

C Sherlaw-Johnson,

senior research fellow

S Gallivan,

professor of

operational research

Division of

Pathology,

University of

Nottingham,

Queen's Medical

Centre, Nottingham

NG7 2UH

D Jenkins,

reader in pathology

Correspondence to: Dr Sherlaw-Johnson c.sherlaw-johnson@ ucl.ac.uk

BMJ 1999;318:356-61

\begin{abstract}
Objective To evaluate the impact of policies for removing women before the recommended age of 64 from screening programmes for cervical cancer in the United Kingdom.

Design A mathematical model of the clinical course of precancerous lesions which accounts for the influence of infection with the human papillomavirus, the effects of screening on the progression of disease, and the accuracy of the testing procedures. Two policies are compared: one in which women are withdrawn from the programme if their current smear is negative and they have a recent history of regular, negative results and one in which women are withdrawn if their current smear test is negative and a simultaneous test is negative for exposure to high risk types of human papillomavirus.
\end{abstract}

Setting United Kingdom cervical screening programme.

Main outcome measures The incidence of invasive cervical cancer and the use of resources.

Results Early withdrawal of selected women from the programme is predicted to give rise to resource savings of up to $25 \%$ for smear tests and $18 \%$ for colposcopies when withdrawal occurs from age 50, the youngest age considered in the study. An increase in the incidence of invasive cervical cancer, by up to
2 cases/100 000 women each year is predicted. Testing for human papillomavirus infection to determine which women should be withdrawn from the programme makes little difference to outcome. Conclusions This model systematically analyses the consequences of screening options using available data and the clinical course of precancerous lesions. If further audit studies confirm the model's forecasts, a policy of early withdrawal might be considered. This would be likely to release substantial resources which could be channelled into other aspects of health care or may be more effectively used within the cervical screening programme to counteract the possible increase in cancer incidence that early withdrawal might bring.

\section{Introduction}

The UK's national coordinating network for cervical screening recommends that all women between the ages of 21 and 64 attend for screening once every 3 to 5 years. ${ }^{1}$ It has been suggested, however, that some women could be withdrawn from the screening programme before age $64^{2}$ because although over half of all cases of invasive cervical cancer occur among women aged over $50,{ }^{3}$ few have been found in women with histories of regular smear tests with normal results. ${ }^{2}$ Additionally, there is evidence that women with certain types of 